\title{
Biological Principles and Threshold Concepts for Understanding Natural Selection
}

\section{Implications for Developing Visualizations as a Pedagogic Tool}

\author{
Lena A. E. Tibell ${ }^{1}$ • Ute Harms ${ }^{2}$
}

Published online: 20 November 2017

C) The Author(s) 2017. This article is an open access publication

\begin{abstract}
Modern evolutionary theory is both a central theory and an integrative framework of the life sciences. This is reflected in the common references to evolution in modern science education curricula and contexts. In fact, evolution is a core idea that is supposed to support biology learning by facilitating the organization of relevant knowledge. In addition, evolution can function as a pivotal link between concepts and highlight similarities in the complexity of biological concepts. However, empirical studies in many countries have for decades identified deficiencies in students' scientific understanding of evolution mainly focusing on natural selection. Clearly, there are major obstacles to learning natural selection, and we argue that to overcome them, it is essential to address explicitly the general abstract concepts that underlie the biological processes, e.g., randomness or probability. Hence, we propose a twodimensional framework for analyzing and structuring teaching of natural selection. The first - purely biological — dimension embraces the three main principles variation, heredity, and selection structured in nine key concepts that form the core idea of natural selection. The second dimension encompasses four so-called thresholds, i.e., general abstract and/or nonperceptual concepts: randomness, probability, spatial scales, and temporal scales. We claim that both of these dimensions must be continuously considered, in tandem, when teaching evolution in order to allow development of a meaningful understanding of the process. Further, we suggest that making the thresholds tangible with the aid of appropriate kinds of visualizations will facilitate grasping of the threshold concepts, and thus, help learners to overcome the difficulties in understanding the central theory of life.
\end{abstract}

The Swedish Research Council (VR 2012:5344, LT) supported this research.

Lena A. E. Tibell

lena.tibell@liu.se

1 Department of Science and Technology, Linköping University, 60174 Norrköping, Sweden

2 IPN - Leibniz Institute for Science and Mathematics Education, Olshausenstraße 62, 24118, 24098 Kiel, Germany 


\section{Introduction}

Darwin's theory of evolution is considered to be one of the most important and ground-breaking theories in science history and it essentially underpins all modern biology, from ecology to medicine. Evolutionary theory explains how all known life forms are related, descended from a common ancestor, diversify, and adapt to their environments. Therefore, sound understanding of evolutionary theory is essential for both understanding many aspects of fundamental science and diverse challenges facing individuals, communities, and global ecosystems today.

In a recent meta-analysis of literature published between 2000 and 2014, Glaze and Goldstone (2015) identified the following seven general orientations in evolution education research: (1) approaches to evolution in the classroom; (2) knowledge, understanding, and acceptance of evolution; (3) attitudes and perceptions of evolution;(4) factors impacting the teaching and learning of evolution; (5) evolution conflicts and coping strategies; (6) evolution and religiosity; (7) evolution teaching methods, courses, and assessment. This clearly indicates that teaching evolution has many facets. Evolution education research has also shown that the theory of evolution presents severe problems to learners, and many teaching strategies have failed to solve them, or reportedly address them ineffectively (e.g., Gregory 2009; Smith 2010a, b; Kampourakis and Zogza 2009). Hence, it is non-controversial that new instructional approaches are needed to foster better conceptual understanding of evolution in biology classroom and wider society. There is therefore an urgent need to find explanations for the difficulties in understanding this fundamental theory of life and ways to overcome them.

Against this background, taking into account (i) recent science education literature on evolution teaching and learning, (ii) threshold concepts (Meyer and Land 2005; Ross et al. 2010), and (iii) findings from cognitive psychology studies, we propose a two-dimensional framework of principles, associated key concepts and threshold concepts pertaining to evolution, particularly natural selection. We hypothesize that a complete understanding of the theory of biological evolution requires development of the ability to freely navigate the complexity of this twodimensional framework. We then hypothesize that appropriate dynamic and multimodal visualizations may serve as educational tools that reduce the thresholds and, thereby fostering learning of evolution in biology classrooms and facilitating students' efforts to grasp the complexity of life.

\section{Basic Problems in the Teaching of Evolution}

The teaching and learning of evolution has faced difficulties ranging from pedagogical obstacles to social controversy, as noted, for example, by Smith (2010a, b). These include two distinct sets of problems. One derives from objections rooted in religion (e.g., Billingsley et al. 2015; Basel et al. 2014; Rissler et al. 2014; Basel et al. 2013; Yasri and Mancy 2012), while the other stems from the fact that many evolutionary concepts may seem, at least initially, counter-intuitive to students. An overview of these problems is given by Kampourakis (2014). In this article, we do not address the first set, but focus on the second.

Previous literature has defined the basic concepts of evolution (e.g., Mayr 1982, 1997; Anderson et al. 2002; Nehm and Reilly 2007) and strenuous efforts have been made to analyze and describe students' difficulties in comprehending them. However, in addition to understanding the concepts constituting the theory of evolution, they must also be connected in a complex web of manifold interconnected systems to thoroughly grasp the theory. Creating these connections may be one of the main problems for learners. Students may struggle to 
assimilate the vast amounts of information they encounter in biology classes, and thus, fail to notice relevant connections between contents and topics, or grasp the concepts that weave them together. Consequently, contents across lessons or classes can appear ambiguous or disconnected (Tenenbaum et al. 2011) and students may not successfully develop an interconnected biological knowledge structure leading to the understanding of evolution. As biological contents can only be fully understood in the integrative framework of biological evolution, it seems essential to use this framework continuously for teaching biology from the beginning onwards (Nehm and Schonfeld 2007; Smith et al. 2009; Leopoldina 2017).

The problem of knowledge integration, i.e., how to integrate newly learned content with existing knowledge, and link, connect, distinguish, organize, and structure ideas (Clark and Linn 2003, p. 452), has been tackled by numerous studies. The effectiveness of knowledge integration depends, among other factors, on the learner's particular knowledge structure, which has been described as efficient if structured around core ideas (e.g., Bransford et al. 2000; Pugh and Bergin 2006), i.e., the central ideas in a focal discipline, such as evolution in biology (NGSS 2013). To support knowledge integration (sensu Clark and Linn 2003) in science education, core ideas have been introduced into the science standards and curricula of several countries, e.g., the USA (NGSS 2013) and Germany (KMK 2005). As a core idea, evolution can support the learning of biology by facilitating the organization of knowledge. In addition, evolution can function as a pivotal link between biological contents and highlight similarities in the complexity of the discipline. In this manner, core ideas are thought to facilitate integration of students' knowledge and understanding of science. However, the extent to which this goal is achieved depends on the coherence (Fortus and Krajcik 2012) with which concepts like evolution are taught across different (disciplinary) contexts (Fortus et al. 2015).

\section{Principles and Key Concepts Linked to Natural Selection}

Evolution is the theory that explains how populations of organisms by random genetic changes generate various new heritable characteristics over generations which, through the action of natural selection, result in adaptation to their environments. As convincingly argued by Darwin and Wallace (Darwin 1859; Smith and Beccaloni 2008), natural selection acts on populations of organisms with various traits and explains how populations change over time as a result of changes in their environments. Thus, natural selection can be described as the differential survival and reproduction of individuals in populations. The variation between individuals within a population originates from genetic variation, and natural selection acts on the resulting phenotypic variation in a biological population. This leads to changes in the frequency of populations' heritable traits in the course of time. Thus, to quote Nei (2005 and 2013) "without mutation no evolution can occur"'and evolutionary relationships among species are generally traced nowadays by comparing their nucleotide sequences (Eterovic and Santos 2013). Genetic processes such as genetic drift is excluded for it mainly affects only small populations. This - in our view - makes it negligible in this context.

Various core and key concepts have been described in the literature for understanding natural selection. One of the most influential expositions was offered by Mayr (1997), which was subsequently elaborated by other researchers, for example, Anderson et al. (2002) and Nehm and Reilly (2007). We have chosen to amalgamate these concepts into three overarching principles — variation, heredity, and selection (cf. Godfrey-Smith 2007)—which are described in detail below, together with the related key concepts as summarized in Table 1. In the following sections, we explain the reasoning behind this organization. 
Table 1 Principles and associated key concepts of natural selection

Principles Associated key concepts (in italics)

Variation Genetic changes (origin of variation) cause individual (phenotypic) variation in survival potential and reproductive potential leading to differential fitness.

Heredity Heritable traits are passed from parent to offspring in reproduction.

Selection Selection pressure and differential survival and reproduction lead to persistent changes within populations and eventually speciation.

\subsection{The Variation Principle}

Natural selection will only lead to evolution if there is genetic variation in a population. Such genetic variation may be manifested as morphological, physiological, or behavioral (phenotypic) differences among the population's members, but we know that the ultimate sources of variation are random mutations, genetic recombination, or horizontal gene transfer, and in sexually reproducing organisms, recombination of genes. Thus, these various changes in the organisms' genomes are the origins of variation. The complete set of genes within an organism's genome, the genotype, lays the foundation for its structure and behavior (phenotype), and hence, the likelihood that it will survive and reproduce, relative to that of other members of its population, in a specific environment (differential fitness). This individual variation (including reproductive capacity) is a fundamental requirement for natural selection (cf. Table 1). However, individual phenotypic variation within populations is a much easier concept to grasp than genetic variation. It should be noted that all mutations contribute to genetic variation, but they do not all give rise to different phenotypes. This is because some mutations occur in non-coding regions of the genome or do not cause any functional changes to gene products. Furthermore, some mutations may be beneficial in some environments, lethal in others, and have changing consequences in a changing environment.

\subsection{The Heredity Principle}

A requirement for the process of natural selection is for individuals to reproduce and pass on their genomes from generation to generation (inherited variation). An important theoretical concept is the biotic potential of a population, which is a measure of its maximum reproductive capacity under optimal (i.e., most favorable) environmental conditions. A population of a species realizing its biotic potential would grow exponentially. If more offspring are produced that can possibly survive in a given environment, competition will occur between the organisms for survival and reproduction. Hence, traits that confer fitness (likelihood to survive and reproduce) in that environment, and that confer advantages over their competitors, are most frequently passed to, and accumulate in the next generation (Anderson et al. 2002; Mayr 2001; Nehm and Reilly 2007; Nehm and Ha 2011) (cf. Table 1).

\subsection{The Selection Principle}

The physical world imposes limits to the individual organisms on which traits that are beneficial. Numerous biotic and abiotic factors determine which potential phenotypic (and hence, genotypic) changes will be beneficial or harmful for organisms, and thus, influence their fitness. These selection pressures may include forms and abundance of diverse nutrients, and presence of 
signaling molecules, toxic agents, pathogens, symbioses, predators, or climate variables (Arthur 2002). Thus, in any environment, differential survival can occur, and organisms with traits that confer advantages over their competitors, in their specific environment, will have a higher probability to survive long enough to reproduce, i.e., different traits confer different survival rate and differential reproductive success. Hence, organisms that have advantageous traits (and the genes that confer them) will be selected. Selective pressures are constantly present, and constantly change within certain ranges, in real environments. This process of natural selection may involve many generations, since individuals with favorable characteristics may gradually come to dominate a population, or very rapidly if (for instance) massive chromosomal re-arrangements or major environmental shifts that eliminate most individuals in a population are involved.

Clearly, organisms inherited reproductive potential and mating success (differential reproduction) are also critical. A short-lived individual that produces numerous offspring may contribute much more to coming generations than long-lived individuals that produce few offspring. As a result, populations evolve in particular directions (Godfrey-Smith 2007) population change. Furthermore, isolated populations (originating from the same ancestral population) may diverge sufficiently over time to become separate species that can no longer interbreed - a process called speciation. In addition, species with unfavorable characteristics might completely die out, like (for example) saber-tooth tigers. The extinction of these animals is believed to have been linked to the contemporaneous decline of large herbivores they preyed upon, and their inability to adapt sufficiently quickly, although other factors such as climate changes and/or competition with humans for prey may also have contributed.

In summary, natural selection is dependent on expressed traits originating from random genetic variation in a population. Different traits confer different survival potentials. However, selection is not random. In a given environment, individuals with advantageous phenotypes will have a high chance to survive and to reproduce (i.e., be selected). Thus, the probabilities of individuals' traits and the associated genes being passed to following generations depend on their reproductive success in their environment, and, i.e., differential reproduction. Selection pressures induce changes in populations' genotypes and associated phenotypes; thus, isolated populations of the same population under different selection pressures may diverge sufficiently to become different species. Natural selection education should embrace all of these key concepts, explicitly clarifying their interrelationships and relevance to the principles of natural selection (Godfrey-Smith 2007), as described above and summarized in Table 1.

However, we argue that in teaching about natural selection, it is not sufficient to consider solely the purely biological concepts that underpin the respective complex theory. In our understanding, the problems of learning natural selection lie "under the surface of biology", i.e., there are other, more general concepts that must be understood in order to grasp the evolutionary concepts. However, as yet, these have remained mostly "hidden" or implicit in natural selection education, which may impede conceptual understanding of evolution. We hypothesize that these are fundamental threshold concepts for teaching and learning the theory of both natural selection and evolution generally.

\section{Threshold Concepts for Understanding the Principles and Key Concepts of Natural Selection}

Conceptual change theory (e.g., Posner et al. 1982) has long been widely applied to describe and predict learning in science education (Duit and Treagust 2003). Here, following Piaget, 
learning is described as a process of either "assimilation" or "accommodation". The process of "assimilation" means that a new concept is harmonized within an individual's existing knowledge structure. The process of "accommodation" means that an individual's knowledge structure changes, and thus, includes the new information resulting in an altered knowledge structure. A decade ago, Meyer and Land (2005) proposed a further approach to explain the learning of complex concepts, such as natural selection and evolution, based on a model of socalled threshold concepts with a non-concrete, abstract nature. They defined these concepts metaphorically as portals that, once passed by a learner, open up new, previously inaccessible ways to develop knowledge. Conceptual change theory and the threshold concept model jointly imply that knowledge of the threshold could be essential for the conceptual change required to gain knowledge of a particular content. In this respect, evolutionary theory can be regarded as resting on a conglomerate of several threshold concepts, like randomness, probability, temporal scales, and spatial scales (Ross et al. 2010) that must be understood in order to understand evolution generally and natural selection specifically.

A potential characteristic of threshold concepts is that they are challenging or troublesome. However, when understood, they open up new ways of thinking that were not previously possible and enable new extended understandings of the subject matter. Such concepts can resolve troublesome ideas that appear alien or counter-intuitive to students, giving rise to periods of conceptual stasis and "failure to learn". This transformation may take time or may be sudden, but it ultimately leads to a scientifically correct understanding of the content. Such transformations of internal views are typical for ontological and cognitive shifts that are also often accompanied by the students' use of a more advanced language. Thus, once understood, threshold concepts profoundly alter the fundamental perception of a given subject, resulting in a conceptual change or even a paradigm shift. In addition of being challenging, in this way, they are transformative. They are also integrative, since they provide previously blocked insights into the subject and connections between topics. A further characteristic feature of threshold concepts is irreversibility; once their meaning has been learnt, it is unlikely to be forgotten (Meyer and Land 2005).

In biology, the threshold concepts are often tacit understandings of the discipline (Ross et al. 2010) and not explicitly taught (Perkins 2006). However, this seems definitely necessary, since for example, Fiedler et al. (2017) have shown that understanding randomness in a mathematical context manifests another ability than grasping randomness in an evolutionary context. Thus, we need to look beyond the biological content, to how the threshold concepts operate in the discipline, and make them explicit to students. There are indications that threshold concepts include abstract concepts that are not necessarily specific to natural selection, but vital for grasping its principles, and these concepts must be pointed out in parallel with the key concepts of natural selection. Concepts that may hinder the learning of natural selection include temporal scale (Catley and Novick 2009; Cheek 2012), spatial scale (Kalinowski et al. 2010), probability, and randomness (Garvin-Doxas and Klymkowsky 2008; Mead and Scott 2010; Robson and Burns 2011). Ross et al. (2010) have also proposed several biological concepts that they distinguish from being only biological concepts because they concern more fundamental and general aspects of natural science. Since the variation in populations depends on random mutations in the genes, another threshold concept might be randomness (Bazil et al. 2016). However, we have chosen to treat genetic variation in connection with the origin of variation, which in turn is a random process.

In the following sections, we focus on four threshold concepts, randomness, probability, temporal scale, and spatial scale. In conjunction with the previously identified principles and 
associated key concepts, this results in a two-dimensional framework for evolution education, as the threshold concepts are orthogonal to the key concepts and principles, in the sense that they are important elements of numerous key concepts in many disciplines (Fig. 1). Using this model, in the following sections, we elaborate on the relations between the key concepts and the threshold concepts. In addition, we discuss implications of the complex nature of natural selection and the operation of evolutionary processes across multiple organizational levels (Table 2) and scales.

\subsection{Randomness and Probability}

Following reports of students' difficulties by various authors, we concluded that probability and randomness are threshold concepts for understanding natural selection (e.g., Mead and Scott 2010; Robson and Burns 2011). These difficulties appear to be rooted in deep-seated misconceptions about random processes, which may lead people (inter alia) to interpret unusual coincidences as paranormal because they misunderstand the probability of their occurring by chance (Paola 2002). For example, Garvin-Doxas and Klymkowsky (2008) found that students tend to believe that random processes are inefficient, but biological processes such as mutations and selection collectively result in evolutionary developments that appear well organized and efficient. They found an almost total absence of understanding of the counter-intuitive fact that random processes happen all the time and can give rise to complex outcomes that can appear directed if one does not consider the effect of selection. Clearly, this could seriously hinder understanding of the role of random variation.

Randomness is defined here as the lack of pattern or predictability in events. A random sequence of events does not follow an intelligible pattern or combination (Bennett 1998) and individual random events are by definition unpredictable. In the context of natural selection, the origins of variation, mutations, are chance events, i.e., random (Table 2). Other kinds of random events that affect populations are accidental death or non-reproduction of individuals in a population (i.e., deaths or failure to reproduce that is not directly related to individuals' genetic make-up or selection pressures), and more generally any stochastic events that randomly reduce (or increase) individuals' fitness. We believe that randomness could be a

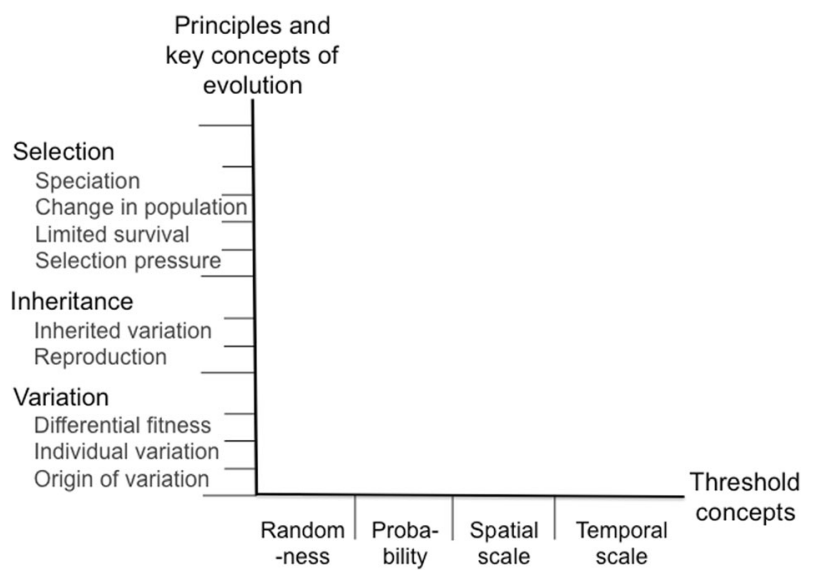

Fig. 1 The two-dimensional framework for teaching and learning evolution integrating biological principles with relevant key and threshold concepts 
Table 2 Interrelations between the three principles and the key concepts of natural selection and the interweaving threshold concepts

\begin{tabular}{|c|c|c|}
\hline Threshold concepts & Principle(s) & Key concepts and examples from natural selection \\
\hline Randomness & Variation & $\begin{array}{l}\text { Origin of variation - random mutations and related gene-level } \\
\text { processes. } \\
\text { Random accidental deaths, failure to reproduce, and other } \\
\text { stochastic events that change individuals' fitness. }\end{array}$ \\
\hline \multirow[t]{2}{*}{ Probability } & Variation & $\begin{array}{l}\text { Differential fitness-different traits confer different } \\
\text { probabilities of individuals' survival and reproduction. }\end{array}$ \\
\hline & $\begin{array}{l}\text { Inheritance and } \\
\text { selection }\end{array}$ & $\begin{array}{l}\text { Differential survival/ reproduction - the probability of an } \\
\text { individual to reproduce depends on the probabilities of } \\
\text { a set of conditions, e.g., survival to a fertile age. }\end{array}$ \\
\hline \multirow[t]{3}{*}{ Temporal scale } & Variation & $\begin{array}{l}\text { Variation arises from causal chains of events that manifest } \\
\text { at different timescales: variation-generating events (origin } \\
\text { of variation, e.g., mutation and recombination) happen at } \\
\text { instantaneous timescales and cause individual variation } \\
\text { that affects organisms' survival and reproduction } \\
\text { probabilities over minutes to years, and hence, } \\
\text { population-level variation (over timescales up to millions } \\
\text { of years). } \\
\text { Inheritance and reproduction happen on the } \\
\text { "one-generation" time scale (i.e., at taxon-specific } \\
\text { generational timescales). }\end{array}$ \\
\hline & Selection & $\begin{array}{l}\text { A certain selection pressure has to be reasonably } \\
\text { unchanged over several generations for selection to } \\
\text { operate and give rise to a change in the population } \\
\text { (i.e., effects of selection pressures depend on their } \\
\text { constancy, duration, and initial states of affected } \\
\text { populations). }\end{array}$ \\
\hline & $\begin{array}{l}\text { Inheritance and } \\
\text { selection }\end{array}$ & $\begin{array}{l}\text { Population changes and speciation occur generally } \\
\text { over many generations (at timescales from hours } \\
\text { to millions of years). }\end{array}$ \\
\hline \multirow[t]{3}{*}{$\begin{array}{l}\text { Spatial scale (and } \\
\text { levels of organization) }\end{array}$} & Variation & $\begin{array}{l}\text { Variation arises from causal chains of events at multiple } \\
\text { organizational levels: nano-scale variation-generating } \\
\text { events (e.g., mutation and recombination) cause } \\
\text { individual level variation at the micrometer to meter } \\
\text { scale leading to population-level variation at } \\
\text { micrometer to global scale. }\end{array}$ \\
\hline & Inheritance & $\begin{array}{l}\text { Reproduction (and thus, inheritance) happens at the } \\
\text { organism level (micrometer to meter scale) }\end{array}$ \\
\hline & Selection & $\begin{array}{l}\text { Population changes and speciation have geographical } \\
\text { distributions that can range from sub-meter to } \\
\text { continental scales. }\end{array}$ \\
\hline
\end{tabular}

threshold concept that, if grasped, would lead to new ways of perceiving biological variation, and hence, natural selection, and that explanations lacking a consideration of randomness may lead to teleological reasoning about variation, for example, that variation occurs as a direct response to a need evoked by the environment.

Probability is defined as a measure of the likeliness that an event will occur and quantified as a number between 0 and 1 (where 0 indicates impossibility and 1 indicates certainty) (Feller 1968). The higher the probability of an event, the more likely it is to occur. Probability is closely related to randomness (Fig. 1), but while randomness describes the uncertainty of an outcome of a single event, probability concerns the relative distribution of possible outcomes of multiple events. Given a single opportunity, something with a low probability is very 
unlikely to happen. However, when the number of events is increasing, the chances increase that one of the events will result in the specific outcome, and therefore, probability is closely related to temporal scale (many generations). Therefore, with a large population reproducing across many generations, a rare and beneficial mutation is likely to happen, but the probability to occur in a single individual will be very low.

In evolution by natural selection differential fitness, differential survival and differential reproduction are all probabilistic. Therefore, "survival of the fittest" is a probabilistic rather than random process (Table 2). Natural selection can be thought of as a lethally rigorous, realworld testing process for evaluating the effect of different random variations in the gene pool of a population; i.e., the adaptation of an organism to a new environment can intuitively be perceived as ordered and purposeful, but is in fact dependent on random genetic variation and the process of selection, which is non-random but affected by probabilistic events. Deterministic reasoning, due to failure to separate these concepts, is common among learners (e.g., Bishop and Anderson 1990). The transition to probabilistic thinking about selection could disfavor non-scientific explanations such as only good traits are inherited, natural selection is an event, or that natural selection always leads to the "better" (e.g., stronger, bigger or faster, and/or more complex organisms) rather than better-adapted (potentially weaker, smaller, slower ,and/or simpler) organisms (e.g., Nehm and Reilly 2007; Nehm et al. 2010; Gregory 2009; Hiatt et al. 2013; and Leonard et al. 2014, and Smith 2010a, b.) Probability is also a threshold concept for understanding inherited variation (Fig. 1). Probabilistic understanding of inheritance facilitates the formulation of new models where traits are not inherited solely deterministically but also stochastically.

It should be noted that even if the genetic processes leading to variation occur at random positions in the genomes, the probability for a certain mutation to arise in a population of a given size in a given number of generations can be calculated, but a specific mutation is highly unlikely to arise in a specific individual. Furthermore, even if one can predict the chance of a specific mutation occurring, the chance of a novel trait emerging cannot usually be predicted (unless the effects of specific mutations in that taxon, or sufficiently related taxa, are known) since natural selection is not deterministic.

\subsection{Temporal and Spatial Scales}

Both scientists and science educators have recognized the importance of size and scale for the ability to reason with scientific concepts, models, and systems. However, the teaching and learning of concepts related to size and scale present major challenges. For example, Swarat et al. (2011) identified three major ways students conceive scale: linear (representing direct observation or experience), proportional, and logarithmic. They found that the most difficult of these categories for students to grasp was the logarithmic scale, but the largest problem was connecting different levels of organization or timeframes.

A dominant framework in chemistry education is the level-based description of representations (Johnstone 2010): the macro-level, the sub-micro level, and the symbolic level. Macrolevel phenomena and properties can be experienced with our senses, while the atomic processes underlying these directly observable phenomena occur at the sub-microscopic level, which must be represented using models, diagrams, or graphs. At the symbolic level, the external representations involve symbols such as letters for atoms, plus and minus signs for charge, and arrows for equilibria. Analogous examples in biological contexts include explanatory mechanisms, schemata and flow diagrams at the symbolic level, representations similar 
to those in chemistry at the sub-micro level, tissue, organs, and whole organisms at the macrolevel (Knippels 2002; van Mil et al. 2016). However, biology requires additional levels (Tsui and Treagust 2012), the micro-level, organelles and cells, and the meso-level, the scale of molecular structures in which cellular biochemical processes occur (Alberts 1998; Hartwell et al. 1999). Associating structurally and functionally related content areas, levels of organization and timescales are mentally demanding (Magana 2014; Magana et al. 2012; Niebert and Gropengiesser 2015), and biological natural selection encompasses the most extreme ranges of scales and complexity (because any biological phenomena can be considered in evolutionary frameworks).

As pointed out by Ferrari and Chi (1998), understanding natural selection requires understanding of multiple levels of organization, and the temporal and spatial scales of natural selection processes respectively range from nanoseconds to millions of years and from molecules to continents. Integrating those scales in natural selection contexts poses major educational challenges. The evolution of species is dependent on variation caused by events like mutations at the molecular level. For example, the phenotypic variations in a rabbit population manifest at the meter scale, but the variation originates from molecular-scale events, while migration and the emergence of new species occur at geographic or population scales. In addition, these processes span temporal scales ranging from essentially instantaneous to deep time. Consequently, integration of multidimensional information across diverse temporal and spatial scales is required to understand natural selection (Fig. 1). Similarly, environmental selection pressures may operate at widely differing organizational levels (spatial scales), from molecular (e.g., exposure to a toxin), through meter scale (e.g., presence of a predator), to global (e.g., climate change). Thus, the ability to connect causal events across scales ranging from molecular to geographic, i.e., at different organizational levels, is crucial for comprehending biological natural selection.

Athanasiou and Mavrikaki (2014) recently compared the knowledge of biological evolution among novice and advanced university students, using the Concept Inventory of Natural Selection (CINS) instrument (Anderson et al. 2002). They found that the most wellunderstood aspects of evolution among novices were individual variation in a population and inheritance of traits, both of which are relatively easy to relate to from personal experience. The least well-understood aspects were the origin of variation, differential survival potential, and origin of species. Only 20-30\% of the novices chose the correct alternatives for items testing these aspects. The most problematic concept for advanced students was biotic potential. Most of these difficulties might be explained by problems in understanding the threshold concepts.

Connecting processes at different organizational levels has been shown to be problematic in chemistry and genetics education (Johnstone 1991; Bahar et al. 1999; Knippels et al. 2005). In accordance with Andersson and Wallin (2006) and Jördens et al. (2016), we propose that there are similar difficulties in the context of evolution education. Furthermore, we propose that there may be an analogous difficulty in connecting different timescales.

In summary, some of the reported difficulties in understanding natural selection might be grounded in difficulties in overcoming the proposed thresholds (Fig. 1, Table 2). If so, grasping the key concepts alone could be insufficient for successful understanding of natural selection. For example, knowing that variation exists in populations is not sufficient; one must also appreciate the underlying stochastic factors. Thus, introducing and emphasizing threshold concepts in parallel with key concepts in natural selection education may be essential, but this raises questions about the optimal way(s) to do this, which we address in the following sections. 


\section{The Threshold Concepts and Complexity of Natural Selection}

Natural selection is an extremely complex probabilistic phenomenon that involves random processes, or at least processes with varying degrees of stochasticity (e.g., mutation, mating, and accidental death) that lead to profound self-organizing and emergent changes in populations of organisms over vast (and diverse) scales of space and time (Chi et al. 2012). The complexity is illustrated by the interactions among genetic changes, physiological and developmental processes involved in phenotypic expression, myriads of environmental factors, fitness, survival, and (hence) selection pressures, all of which involve highly complex processes and vary massively over space and time. This complexity is usually described on the level of the key biological concepts and principles of natural selection outlined above, but closer examination reveals potential obstacles linked to the identified threshold concepts. For example, to grasp the causal chain leading from genotype to phenotype, one must follow the track from an individual organism's DNA sequence, including mutations, to the complete organism's physical, physiological, or behavioral traits (Kirschner et al. 2006). Also, Smith et al. (2009) and White et al. (2013) have recommended the so-called integrative cases, in which genes-to-selectable-phenotype pathways are described in the context of evolution. The central parts of this causal chain lie in the so-called micro-, meso-, and sub-micro scales.

The events that occur at sub-micro and meso-scales are dynamic, complex, and generally less well understood than phenomena at the micro and macro scales. In addition, many traits are "quantitative" (i.e., measurable, dependent on multiple genes and interactions between both the resulting proteins and environmental factors, and thus, not subject to simple Mendelian inheritance patterns). If a trait is an effect of a single genetic change (for example, a mutation causing sickle cell anemia), the relation between genotype and phenotype is relatively simple to illustrate. However, large parts of the genotype-to-phenotype pathway(s) are frequently neglected, avoided, taken for granted, or implicitly indicated in teaching natural selection. Genetics instruction in introductory biology courses is often confined to Mendelian genetics and avoids the complexities of variation in quantitative traits (Batzli et al. 2014) and the replication of DNA (inheritance of genotype), its transcription and translation (production of proteins) are often taught in isolation and with weak connection to natural selection. To help learners grasp these complexities, Andersson and Wallin (2006) and Knippels (2002) have argued that a "yo-yo approach" is needed, in which each level of organization is addressed, and moves between different levels are explicitly explained and displayed. Recently, Jördens et al. (2016) described several problems related to disconnection and confusion between levels. They claim that vertical connections are necessary in the context of evolution.

Clearly, interweaving of the natural selection principles and key concepts with the threshold concepts strongly contributes to the complexities involved. We argue that the complex structure of natural selection concepts is very difficult to grasp by merely considering the pure biological "surface" level phenomena, and that the threshold concepts must be made tangible to perceive and grasp their significance.

In summary, the threshold concepts described above share one or more of the following characteristics. They are non-perceptible, abstract, and often appear to lead to counter-intuitive results. Neglect, trivialization, or over-simplification of these concepts frequently leads to scientifically incorrect or teleological conclusions. Thus, we propose an extended framework that is not restricted to biological concepts but integrates the threshold concepts in a structured manner. We argue that using this framework in the development of instructional tools could improve understanding of biological evolution. We also suggest that natural selection 
education should incorporate threshold concepts, and the complexity of natural selection should be confronted using it as the unifying core idea of biology.

\section{Visualizing the Threshold Concepts-an Approach to Teach the Complexity of Natural Selection}

Progress in understanding science has been shown to be tightly connected to the ability to model abstract and complex content (e.g., Kozma et al. 2000), and one way to do this is through visualizations. Visual representations in science are characteristically very broad and highly heterogeneous. They may depict more complex phenomena monitored by other instruments or be displayed in imaginary schemes, diagrams, mathematical relationships, or computer renderings. Dynamic visualizations are those in which the graphical elements are displayed and change with time. Animations and simulations are examples of dynamic visualizations, and we also include videos and computer games in this category. Animations might be based on simulations, but like videos, they can only be manipulated by starting, stopping, and rewinding them. In contrast, simulations and computer games are interactive and can be manipulated in more diverse ways during their execution. Recent developments in digital media also allow combinations of machine-generated and handmade representations.

Visual representations have been shown to be useful tools for making abstract content comprehensible (Niebert and Gropengiesser 2015) for learners. In fact, research indicates that to develop an integrated understanding of matter, it is important for students to be able to represent and interpret visualizations and to connect them to observable phenomena (Gilbert and Treagust 2009; Johnstone 1991; Linn 2006). Use of multimedia and computer-mediated instruction can promote students' understanding (e.g., Barnea and Dori 1999; Kozma and Russell 1997; Mayer, 2003a; Wu et al. 2001) and the use of multimedia and computer-mediated instruction can promote students' meaning-making (e.g., Barnea and Dori 1999; Kozma and Russell 1997; Mayer 2003; Wu et al. 2001). Results from the use of such types of multimodal representations indicate a potential to transform students learning (McElhaney et al. 2015). By using multiple representations of the same concept, a simulation can also link the changes in different kinds of representations (e.g., to link manipulation of the DNA sequence to effect at the macromolecular level, which in turn effects the physiology, and finally, eventually changing the phenotype). However, non-interactive media is often not useful for showing phenomena over time, and static illustrations have problems of showing change in populations or giving the whole picture of replication. For the understanding of complex content, such as natural selection, interactive simulations and animations might be helpful.

Animations are valuable when they explicitly depict linear or dynamic changes over time. For example, several studies have shown that participation in a teaching setup including animations can improve students' understanding of molecular movements and dynamics, interactions between molecules, osmosis, and equilibrium (Pallant and Tinker 2004). When animations present dynamic content, they also visualize spatial changes in both position and form and challenge students' (mis-)perceptions emanating from static illustrations (Rundgren and Tibell 2010).

Animations and simulations could therefore be highly useful for illustrating the dynamic processes involved in natural selection, the complex connections between them, and spatialtemporal relations. These aspects pose major challenges, which could be potentially overcome by means of multimedia learning (Mayer 2005). We believe that interactive multimedia 
learning can provide new possibilities to teach and learn about threshold concepts by affording multimodal and multi-scale presentations of information that allow instant feedback, thereby facilitating sense-making.

We have found no studies on dynamic visualization that have focused on threshold concepts in natural selection. In the following section, we exemplify how visualizations, particularly dynamic visual representations, have been used to facilitate learning of threshold concepts and associated phenomena, mostly in other areas, but related to natural selection. We also report observed benefits, shortcomings, and design issues noted in these studies.

\subsection{Randomness and Probability in Visualizations}

In many cases, the problem with understanding natural selection lies in accepting that the mutations that lead to genetic variation occur randomly and are not affected by the environment. Thus, the environment does not bias the random positions for genetic alterations towards those that are beneficial for adaptation. Mutations, which occur on random occasions in a population, are essential for the broad variations in genetic composition that eventually accumulate, and adaptation is a consequence of selection of previously existing variants in populations. However, to our knowledge, no studies have explored ways to visualize the roles of randomness in natural selection. Based on previous studies, exemplified below, we suggest that adequate visual representations, which can explicitly depict the randomness and probabilistic aspects of the processes, are likely to support students' comprehension of them (and hence, of natural selection generally).

Visualization of randomness and probability in educational contexts is relatively scarce and has been mainly studied in mathematics and statistics education using graphs or simulations (Gordon and Gordon 2009). The abstract concepts have usually been applied to objects seen in the scale range that humans can perceive with unaided senses, such as coins or dices (e.g., Capadia and Borovcnik 1991). In most of these cases, the visual representations have been found to be helpful.

One non-digital biological example is a tangible model of a virus that was used to study its effects on students' meaning-making of a sub-microscopic process, the self-organization of a virus capsid (Höst et al. 2013). This process was perceived as counter-intuitive since a virus capsid is created via random collations of subunits. The study indicated that use of the model supported the students' understanding of the random and reversible aspects of the self-assembly process. In fact, the behavior of the model was shown to challenge students' pre-conceptions of the nature of the self-assembly of the virus capsule as a predetermined process (Larsson and Tibell 2015). However, it did not support understanding of the different attractive and repulsive forces involved.

Another example is the study conducted by Haddad and Baldo (2010). Their aim was to show to students that the diffusion rate is high enough to explain transport within cells but too slow for transport between tissues in a multicellular organism. In their investigation, the students (representing the particles in a system) were moving relative to a reference line in several rounds directed by tossing a coin (representing the random movements of the particles). Then, the students had to calculate how many trials were needed for a given student to cover a particular distance. By this experience, the students realized why diffusion causes efficient molecular transport over short distances but becomes increasingly and rapidly less effective as the distance becomes progressively larger.

In another biological context, the utility of an animated graph for communicating the nature of risk of dying due to cardiovascular disease has been explored (Witteman et al. 2014). The 
authors tested various design factors, in varying combinations, and using questionnaires to randomly selected individuals as respondents. Introduction of an avatar as a symbol for individuals and populations appeared to be the best design. This study demonstrates the importance of visual design and choice of modalities for the efficiency of communication. In natural selection contexts, visualizations of trees, patterns, or evolutionary landscapes are ways of typologically handling its roles (Olsson and Østman (n.d.), https:/www.youtube. $\mathrm{com} /$ watch? $\mathrm{v}=4$ pdiAneMMhU). Another example is a simulation by Espinosa and Bai (2011) designed to show probabilities of certain random mutations arising and being selected in a population, and the effects of selection pressures, time (generations), and population size on the probabilities.

Altogether, these studies exemplify how visual representations can be used to help students grasp important abstract concepts, such as randomness, and associated counter-intuitive phenomena. However, since all visualizations concentrate on one or just a few aspects of a phenomenon, they have to be complemented by other visualizations and by explanations as well as further educational support. Deeper analysis is required to identify the optimal designs, the optimal ways to use them, and to elucidate their effects.

\subsection{Temporal and Spatial Scales in Visualizations}

As already mentioned, three levels of organization (macro, sub-micro, and symbolic) have been recognized in level-based descriptions of representations (Johnstone 2010), but biology requires two additional (meso and micro) levels (Tsui and Treagust 2012; van Mil et al. 2016), and natural selection encompasses the most extreme ranges of scales and complexity. Boroditsky (2000) proposed that abstract conceptual domains are structured through metaphorical mappings from domains grounded directly in experience. His results indicate that the domains of space and time share a conceptual structure. Spatial relational information is therefore suggested to be just as useful for thinking about time as temporal information. With frequent use and training, mappings between space and time might lead to thinking about time that does not necessarily require access to spatial schemas. Accordingly, one strategy to handle transitions between scales is by creating representations. One representational approach is to use multiple representations, such as two-dimensional static representations (Ainsworth 1999). However, there is also considerable evidence that learners often fail to take advantage of multiple representations, and that they need to be used in a supportive context (Ainsworth 2008). Multimedia and dynamic visual representations, such as videos and animations, are other approaches for connecting timeframes and illustrating dynamic processes. There are also several reports indicating that visualization is helpful for grasping issues related to size and scale (Mayer 2001).

It has been proposed that various interactive representations, such as simulations, digital learning platforms, and games, may be even more beneficial. For example, Magana (2014) proposed that interactive 3D models with "zoom in zoom out" facilities and direct interactivity with a scale metaphor help students familiarize with objects of different sizes and timescales, and to make the connections explicit (van Mil et al. 2016). Research indicates that these strategies can be beneficial for three reasons according to Ainsworth (1999): (1) representations can complement each other, (2) familiar representations can constrain and explain more unfamiliar ones, and (3) a combination of representations can provide learners with deeper conceptual understanding of topics. The interactive learning environment BioLogica exemplifies this. This is a hypermodel intended to facilitate understanding of connections between 
mutations, genotypes, gene products, and phenotypes. Assessments of BioLogica's educational learning potential concluded that it contributes to the development of students' reasoning skills in the domain by increasing motivation and interest, provided that instruction and feedback are given and scaffolding is supported (Tsui 2003; Buckley et al. 2004).

Many concepts underlying natural selection are both complex and counter-intuitive, e.g., that adaptation and the emergence of new species originate from random mutations. Thus, we suggest that visual representations might be effective tools for interrelating the diverse aspects of natural selection, and integrating them into the network of concepts that underlies modern understanding of evolution. With intelligent guidance to facilitate sense-making in natural selection, the full potential of the media could be realized (inter alia, we believe) by using it in natural selection education to facilitate grasping of connections between conceptualized molecules and populations of real organisms, and events on timescales ranging from nanoseconds to billions of generations.

\subsection{Complexity in Visualizations}

Biological organisms have properties that arise from complex interactions among their own components and diverse external factors. Biological processes involve complex systems operating at multiple, tightly connected levels of organization - from the subatomic, through molecules, cells, tissues, and organs, to individual organisms, whole populations, ecosystems, and biomes. All of these interactions are intimately associated with natural selection (which is why it can be regarded as a core, unifying concept). The systems involved in the process may have different characteristics and functions, but they still share many features, together with both random and ordered elements in their behavior. Hence, they are neither completely deterministic (as in Newtonian mechanics) nor totally random (like motions of particles in statistical mechanics). However, a complex system is dependent on its initial conditions (Mazzocchi 2008). This complexity at multiple levels of organization underlies natural selection. As a whole, this is a major challenge for educators to teach and for students to comprehend, understand, and appreciate.

In fact, several studies indicate that visualizations are valuable tools for communicating complex content to learners. (e.g., Gordin and Pea 1995). For example, Tversky et al. (2002) suggested that dynamic representations may be more effective for communicating complex systems than static representations, and Ainsworth (2008) pointed out that multiple representations are powerful tools to help learners develop complex scientific knowledge. Hence, we conclude that visualizations can be effective tools for communicating the complexity that results from the two-dimensional framework for teaching natural selection described above.

\subsection{Concerns and Visual Design for Learning}

According to the structure-mapping principle (Schnotz 2005; Schnotz and Bannert 2003), pictures and animations only enhance comprehension if the learning content is visualized in a task-appropriate way. Tasker and Dalton (2008) have shown that different people with different prior knowledge perceive different features in an animation, highlighting the need to consider the prior knowledge of the students when using animations. Visualizing abstract and non-perceptual concepts is a particularly demanding task. Both instructional and graphic design must be optimized so that it facilitates learners' understanding, without introducing misleading simplifications, or cognitive overload. Hence, it is very important to consider the 
content, the aim, learners' pre-knowledge (e.g., Neubrand and Harms 2017; Neubrand et al. 2016), and the learning goal of a visualization when investigating the nature of the receivers' comprehension of the message (or seeking to maximize its educational value). Interactivity has been suggested to be one way to overcome some of the problems (Tversky et al. 2002; McElhaney et al. 2015) which are central for understanding the threshold concepts. Randomness and probability are dependent on interactivity in simulations and interactive animations; however, the connection to the evolutionary context is also important. Understanding the temporal scale requires new embodied ways to really grasp the enormous differences in time. A ruler showing the difference between mutation rates and when life on earth emerged is far too simple. Furthermore, videos, animations, and simulations should fulfill at least two criteria when teaching different spatial scale. They should address different levels of organization, and also help students to distinguish between these levels (Jördens et al. 2016).

In summary, for visualizations to be effective, learning tools must be firmly rooted in the knowledge base of the viewer/learner. If the viewer does not possess the knowledge required to understand the graphical entities and the relations between them, visualization will not achieve its goal. Therefore, the visualization has to make connections between the knowledge base of the learner and the knowledge being taught. Consequently, in order to design effective visualizations, it is crucial to consider the nature of the content intended to be communicated and to have knowledge of learners' pre-conceptions. However, variations in both learners' knowledge bases and their internal representations of the visualized phenomena will influence how they interpret visualizations and integrate presented knowledge in their existing knowledge base. In addition, as individuals learn science, they progress from perceptual or realistic to abstract levels of understanding through increasing levels of abstraction and visualization (Mathewson 2005). Such considerations are major foci of the research area Visualization for learning, in which the key practical objective is to identify the most appropriate way to design (multimodal) visualizations tailored to the specific combinations of contents and how to complement these visual tools to efficiently communicate this content.

\section{Conclusions}

We suggest that natural selection education should explicitly focus on threshold concepts and confront the complexity of the topic. Further, we propose that visualization and "perceptualisation" of concepts and processes that are not directly accessible through students' senses (e.g., threshold concepts) might facilitate conceptual change in their understanding of natural selection.

The two-dimensional framework advocated here and the hypothesis that the thresholds need to be rendered tangible for the learners by visualization have several implications. Notably, there is a need to assess whether visualizations of natural selection processes that are used for educational purposes or are available for public use, e.g., via the internet, take into account the threshold concepts. If so, there is then a need to consider how they are expressed and connected to key concepts and principles of natural selection. Such analyses should be accompanied by intervention studies designed to assess effects of these visualizations in teaching and learning settings.

Ideally, this should lead to the establishment of a set of tools, and hence, development of effective dynamic multimodal representations for teaching and learning of biological natural selection. However, no visual representation is likely to be sufficient on its own, as the 
examples summarized above indicate that in order for dynamic digital visualizations to be efficient tools, they must be complemented with appropriate instructional support and feedback for efficient scaffolding. Such support also needs to be developed and combined with the specific visualizations in functional modules for teaching and learning natural selection.

Acknowledgements The authors acknowledge the EvoVis research group; $\mathrm{PhD}$ students Gustav Bohlin, Andreas Göransson, Jörgen Stenlund, Daniel Orraryd, and Daniela Fiedler, Dr. Gunnar Höst, Dr. Konrad Schönborn, Prof. Jan Anward and Prof. Bengt-Harald Jonsson for many and profound discussions. We are also very grateful to Dr. John Blackwell for the language review and valuable and insightful comments on evolution aspects of the paper.

\section{Compliance with ethical standards}

Conflict of interest The author declares no conflict of interest.

Open Access This article is distributed under the terms of the Creative Commons Attribution 4.0 International License (http://creativecommons.org/licenses/by/4.0/), which permits unrestricted use, distribution, and reproduction in any medium, provided you give appropriate credit to the original author(s) and the source, provide a link to the Creative Commons license, and indicate if changes were made.

\section{References}

Ainsworth, S. (1999). The functions of multiple representations. Computers \& Education, 33(2-3), 131-152.

Ainsworth, S. (2008). The educational value of multiple-representations when learning complex scientific concepts. In Visualization: Theory and Practice in Science Education (pp. 191-208). In J. K. Gilbert, M. Reiner, M. Nakhleh (Eds). Surrey, UK: Springer.

Alberts, B. (1998). The cell as a collection of protein machines: preparing the next generation of molecular biologists. Cell, 92, 291-294.

Anderson, D. L., Fisher, K. M., \& Norman, G. J. (2002). Development and evaluation of the conceptual inventory of natural selection. Journal of Research in Science Teaching, 39(10), 952-978.

Andersson, B., \& Wallin, A. (2006). On developing content-oriented theories taking biological evolution as an example. International Journal of Science Education, 28(6), 673-695.

Arthur, W. (2002). The emerging conceptual framework of evolutionary developmental biology. Nature, 415(6873), 757-764.

Athanasiou, K., \& Mavrikaki, E. (2014). Conceptual inventory of natural selection as a tool for measuring Greek university students' evolution knowledge: differences between novice and advanced students. International Journal of Science Education, 36(8), 1262-1285.

Bahar, M., Johnstone, A. H., \& Hansell, M. H. (1999). Revisiting learning difficulties in biology. Journal of Biological Education, 33, 84-86.

Barnea, N., \& Dori, Y. J. (1999). High-school chemistry students' performance and gender differences in a computerized molecular modeling learning environment. Journal of Science Education and Technology, 8(4), 257-271.

Basel, N., Harms, U., \& Prechtl, H. (2013). Analysis of students' arguments on evolutionary theory. Journal of Biological Education, 47(4), 192-199.

Basel, N., Harms, U., Prechtl, H., Weiß, T., \& Rothgangel, M. (2014). Students' arguments on the science and religion issue: the example of evolutionary theory and genesis. Journal of Biological Education, 48(4), 179-187.

Batzli, J. M., Smith, A. R., Williams, P. H., McGee, S. A., Dósa, K., \& Pfammatter, J. (2014). Beyond Punnett squares: student word association and explanations of phenotypic variation through an integrative quantitative genetics unit investigating anthocyanin inheritance and expression in Brassica rapa Fast plants. CBE-Life Sciences Education, 13, 410-424.

Bazil, J. M., Knight, J. K., Hartley, L. M., Maskiewicz, A. C., \& Desy, E. A. (2016). Crossing the threshold: bringing biological variation to the foreground. CBE-Life Sciences Education, 15(es9), 1-7. 
Bennett, D.J. (1998) Randomness. London: Harvard University Press.

Billingsley, B., Brock, R., Taber, K. S., \& Riga, F. (2015). How students view the boundaries between their science and religious education concerning the origins of life and the universe. Science Education., 100(3), 459-482.

Bishop, B. A., \& Anderson, C. W. (1990). Student conceptions of natural selection and its role in evolution. Journal of Research in Science Teaching, 27(5), 415-427.

Boroditsky, L. (2000). Metaphoric structuring. Cognition, 75(1), 1-28.

Bransford, J. D., Brown, A. L., \& Cocking, R. R. (2000). How people learn: brain, mind, experience and school. Washington: National Academy Press.

Buckley, B. C., Gobert, J. D., Kindfield, A. C. H., et al. (2004). Model-based teaching and learning with BioLogica ${ }^{\mathrm{TM}}$ : what do they learn? How do they learn? How do we know? Journal of Science Education and Technology, 13(1), 23-41.

Capadia, R. \& Borovcnik, M. (1991) Editors, Chance encounters: probability in education, Springer Dordrecht.

Catley, K. M., \& Novick, L. R. (2009). Digging deep: exploring college students' knowledge of macroevolutionary time. Journal of Research in Science Teaching, 46(3), 311-332.

Cheek, K. A. (2012). Students' understanding of large numbers as a key factor in their understanding of geologic time. International Journal of Science and Mathematics Education, 10, 1047Y1069.

Chi, M. T. H., Roscoe, R. D., Slotta, J. D., Roy, M., \& Chase, C. C. (2012). Misconceived causal explanations for emergent processes. Cognitive Science, 36(1), 1-61.

Clark, D., \& Linn, M. C. (2003). Designing for knowledge integration: the impact of instructional time. Journal of the Learning Sciences, 12(4), 451-493.

Darwin, C. (1859). On the origin of species by means of natural selection, or the preservation of favoured races in the struggle for life. London: John Murray (1st edition).

Duit, R. H., \& Treagust, D. F. (2003). Conceptual change-still a powerful framework for science education research and development. International Journal of Science Education, 25(6), 1-7.

Espinosa, A., \& Bai, C. Y. (2011). The Jackprot Simulation couples mutation rate with natural selection to illustrate how protein evolution is not random. Evolution: Education and Outreach, 4(3), 502-514.

Eterovic, A., \& Santos, C. M. D. (2013). Teaching the role of mutation in evolution by means of a board game. Evolution: Education and Outreach, 6(1), 1-10.

Feller, W. (1968) An introduction to probability theory and its applications 3rd Ed, New Jersey: Wiley.

Ferrari, M., \& Chi, M. T. H. (1998). The nature of naive explanations of natural selection. International Journal of Science Education, 20(10), 1231-1256.

Fiedler, D., Tröbst, S., \& Harms, U. (2017). University students' conceptual knowledge of randomness and probability in the contexts of evolution and mathematics. CBE-Life Sciences Education (LSE), 16(2), 1-16 ar38.

Fortus, D., \& Krajcik, J. (2012). Curriculum coherence and learning progressions. In B. J. Fraser, K. Tobin, \& C. J. McRobbie (Eds.), Second international handbook of science education (Vol. 24, pp. 783-798). Dordrecht: Springer.

Fortus, D., Sutherland, L., Reiser, B. J., \& Krajcik, J. S. (2015). Assessing the role of curriculum coherence in student learning about energy. Journal of Research in Science Teaching, 52(10), 1408-1425.

Garvin-Doxas, K., \& Klymkowsky, M. W. (2008). Understanding randomness and its impact on student learning: lessons learned from building the biology concept inventory (BCI). CBE Life Sciences Education, 7, $227-233$.

Gilbert, J. K., \& Treagust, D. F. (2009). Introduction: macro, submicro and symbolic representations and the relationship between them: key models in chemical education. In J. K. Gilbert \& D. F. Treagust (Eds.), Multiple representations in chemical education (Vol. 4, pp. 1-8). Dordrecht: Springer.

Glaze, A. L., \& Goldstone, M. J. (2015). U.S. science teaching and learning of evolution: a critical review of the literature 2000-2014. Science Education, 99(3), 500-518.

Godfrey-Smith, P. (2007). Conditions for evolution by natural selection. The Journal of Philosophy, 104(10), 489-516.

Gordin, D. N., \& Pea, R. D. (1995). Prospects for scientific visualization as an educational technology. Journal of the Learning Sciences, 4(3), 249-279.

Gordon, S. P., \& Gordon, S. F. (2009). Visualizing and understanding probability and statistics: graphical simulations using Excel. Mathematics Undergraduate Studies, 19(4), 346-369.

Gregory, T. R. (2009). Understanding natural selection: essential concepts and common misconceptions. Evolution: Education and Outreach, 2(2), 156-175.

Haddad, H., \& Baldo, M.-V. C. (2010). Teaching diffusion with a coin. Advances in Physiology Education, 34, $156-157$.

Hartwell, L. H., Hopfield, J. J., Leibler, S., \& Murray, A. W. (1999). From molecular to modular cell biology. Nature, 402(6761 Suppl), C47-C52.

Hiatt, A., Davis, G. K., Trujillo, C., Terry, M., French, D. P., Price, R. M., \& Perez, K. E. (2013). Getting to evodevo: concepts and challenges for students learning evolutionary developmental biology. CBE-Life Sciences Education, 12(3), 494-508. 
Höst, G. E., Larsson, C., Olson, A., \& Tibell, L. A. E. (2013). Students' learning about biomolecular selfassembly using two different external representations. CBE Life Sciences Education, 12(3), 471-482.

Johnstone, A. H. (1991). Why is science difficult to learn? Things are seldom what they seem. Journal of Computer Assisted Learning, 7, 75-83.

Johnstone, A. H. (2010). You can't get there from here1. Journal of Chemical Education, 87(1), 22-29.

Jördens, J., Asshoff, R., Kullmann, H., \& Hammann, M. (2016). Providing vertical coherence in explanations and promoting reasoning across levels of biological organization when teaching evolution. International Journal of Science Education, 38(6), 960-992.

Kalinowski, S. T., Leonard, M. J., \& Andrews, T. M. (2010). Nothing in evolution makes sense except in the light of DNA. [research support, non-U.S. Gov’t]. CBE Life Sciences Education, 9(2), 87-97.

Kampourakis, K. (2014). Understanding evolution. Cambridge: Cambridge University Press.

Kampourakis, K., \& Zogza, V. (2009). Preliminary evolutionary explanations: a basic framework for conceptual change and explanatory coherence in evolution. Science \& Education, 18(10), 1313-1340.

Kirschner, M. W., Gerhart, J. C., \& Norton, J. (2006). The plausibility of life: resolving Darwin's dilemma (pp. 10-38). New Haven: Yale University Press.

KMK [Ständige Konferenz der Kultusminister der Länder in der Bundesrepublik Deutschland]. (2005). Bildungsstandards im Fach Biologie für den Mittleren Schulabschluss-Beschluss vom 16.12.2004 [Science Standards for Middle School Biology, Germany]. München: Luchterhand.

Knippels, M. C. P. H. (2002). Coping with the abstract and complex nature of genetics in biology education-the yo-yo learning and teaching strategy. Utrecht: CD $\beta$ Press.

Knippels, M.-C. P. J., Waarlo, A. J., \& Boersma, K. T. (2005). Design criteria for learning and teaching genetics. Journal of Biological Education., 39, 108-112.

Kozma, R. B., \& Russell, J. (1997). Multimedia and understanding: expert and novice responses to different representations of chemical phenomena. Journal of Research in Science Teaching., 34(9), 949-968.

Kozma, R., Chin, E., Russell, J., \& Marx, N. (2000). The roles of representations and tools in the chemistry laboratory and their implications for chemistry learning. Journal of the Learning Sciences., 9, 105-143.

Larsson, C., \& Tibell, L. A. E. (2015). Challenging students' intuitions: the influence of a tangible model of virus assembly on students' conceptual reasoning about the process of self-assembly. Research in Science Education, 24(5), 663-690.

Leonard, M. J., Kalinowski, S. T., \& Andrews, T. C. (2014). Misconceptions yesterday, today, and tomorrow. CBE-Life Sciences Education, 13, 179-186.

Leopoldina-Nationale Akademie der Wissenschaften (2017). Evolutionsbiologische Bildung in Schule und Universität [Education in evolution biology in schools and universities]. Deutsche Akademie der Naturforscher Leopoldina e.V. Nationale Akademie der Wissenschaften, Halle (Saale).

Linn, M. C. (2006). The knowledge integration perspective on learning and instruction. In R. K. Sawyer (Ed.), The Cambridge handbook of the learning sciences (pp. 243-264). New York: Cambridge University Press.

Magana, A. J. (2014). Learning strategies and multimedia techniques for scaffolding size and scale cognition. Computers \& Education, 72, 367-377.

Magana, A. J., Brophy, S. P., \& Bryan, L. A. (2012). An integrated knowledge framework to characterize and scaffold size and scale cognition (FS2C). International Journal of Science Education, 34(14), 2181-2203.

Mathewson, J. H. (2005). The visual core of science: definition and applications to education. International Journal of Science Education, 27(5), 529-548.

Mayer, R.E. (2001), Multimedia learning. Cambridge University Press, 2nd Edition . New York: Cambridge University Press.

Mayer, R. E. (2003). The promise of multimedia learning: using the same instructional design methods across different media. Learning and Instruction, 13(2), 125-139.

Mayer, R. E. (Ed.). (2005). Introduction to multimedia learning In the Cambridge handbook of multimedia learning. R.E. Mayer (Ed). Cambridge UK: Cambridge University Press.

Mayr, E. (1982). The growth of biological thought. diversity, evolution and inheritance. Cambridge: The Belknap Press of Harvard University Press.

Mayr, E. (1997). What makes biology unique? Considerations on the autonomy of a scientific discipline. Cambridge: Cambridge University Press.

Mayr, E. (2001). What evolution is. Basic Books. Perseus Book Group, New York.

Mazzocchi, F. (2008). Complexity in biology. Exceeding the limits of reductionism and determinism using complexity theory. EMBO Reports, 9(1), 10-14.

McElhaney, K. W., Chang, H.-Y., Chiu, J. L., \& Linn, M. C. (2015). Evidence for effective uses of dynamic visualisations in science curriculum materials. Studies in Science Education, 51(1), 49-85.

Mead, L. S., \& Scott, E. C. (2010). Problem concepts in evolution part II: cause and chance. Evolution: Education and Outreach, 3, 261-264. 
Meyer, J. H. F., \& Land, R. (2005). Threshold concepts and troublesome knowledge (2): epistemological considerations and a conceptual framework for teaching and learning. Higher Education, 49(3), 373-388.

Nehm, R. H., \& Ha, M. (2011). Item feature effects in evolution assessment. Journal of Research in Science Teaching., 48(3), 237-256.

Nehm, R. H., \& Reilly, L. (2007). Biology majors' knowledge and misconceptions of natural selection. Bioscience, 57, 263-272.

Nehm, R. H., \& Schonfeld, I. S. (2007). Does increasing biology teacher knowledge of evolution and the nature of science lead to greater preference for the teaching of evolution in schools? Journal of Science Teacher Education, 18, 699-723.

Nehm, R. H., Rector, M. A., \& Ha, M. (2010). "Force-talk" in evolutionary explanation: metaphors and misconceptions. Evolution: Education and Outreach, 3(4), 605-613.

Nei, M. (2005). Selectionism and neutralism in molecular evolution. Molecular Biology and Evolution, 22(12), 2318-2342 Erratum in: Molecular Biology and Evolution (2006) 23(5):1095.

Nei, M. (2013). Mutation-driven evolution. New York: Oxford University Press.

Neubrand, C., \& Harms, U. (2017). Tackling the difficulties in learning evolution: effects of adaptive selfexplanation prompts. Journal of Biological Education (JBE)., 51(4), 336-348.

Neubrand, C., Borzikowsky, C., \& Harms, U. (2016). Adaptive prompts for learning evolution with worked examples - highlighting the students between the "novices" and the "experts" in a classroom. International Journal of Environmental \& Science Education, 11(14), 6774-6795.

NGSS Lead States (2013). Next generation science standards: for states, by states. Washington, DC: The National Academies Press.

Niebert, K., \& Gropengiesser, H. (2015). Understanding starts in the mesocosm: conceptual metaphor as a framework for external representations in science teaching. International Journal of Science Education, 37(5-6), 903-933.

Østman, B., \& Olson, R., (2014). Using fitness landscapes to visualize evolution in action. Retrieved from https:/www.youtube.com/watch?v=4pdiAneMMhU. Accessed Nov 15, 2017.

Pallant, A., \& Tinker, R. F. (2004). Reasoning with atomic-scale molecular dynamic models. Journal of Science Education and Technology, 13, 51-66.

Paola, B. (2002). The connection between random sequences, everyday coincidences, and belief in the paranormal. Applied Cognitive Psychology, 16, 17-34.

Perkins, D. (2006). Constructivism and troublesome knowledge. In J. H. F. Meyer \& R. Land (Eds.), Overcoming barriers to student understanding: threshold concepts and troublesome knowledge (pp. 33-48). Routledge: Abingdon.

Posner, G. J., Strike, K. A., Hewson, P. W., \& Gertzog, W. A. (1982). Accommodation of a scientific conception: toward a theory of conceptual change. Science Education, 66, 211-227.

Pugh, K. J., \& Bergin, D. A. (2006). Motivational influences on transfer. Educational Psychologist, 41(3), 147-160.

Rissler, L. J., Duncan, S. I., \& Caruso, N. M. (2014). The relative importance of religion and education on university students' views of evolution in the Deep South and state science standards across the United States. Education and Outreach, 7, 24 http://www.evolution-outreach.com/content/7/1/24.

Robson, R. L., \& Burns, S. (2011). Gain in student understanding of the role of random variation in evolution following teaching intervention based on Luria-Delbruck experiment. Journal of Microbiology \& Biology Education: JMBE, 12(1), 3.

Ross P.M., Taylor, C.E., Hudges, C., Kofod, N., Whitaker, N., Lutze-Mann, Kofod M., and Tzioumis, V., (2010) Threshold concepts in learning biology and evolution, Biology International, 47, 47-52.

Rundgren, C.-J., \& Tibell, L. A. E. (2010). Critical features of visualizations of transport through the cell membrane: an empirical study of upper secondary and tertiary students' meaning-making of a still image and an animation. International Journal of Science and Mathematics Education, 8(2), 223-246.

Schnotz, W. (2005). An integrated model of text and model integration. In M. R. E. (Ed.), The Cambridge handbook of multimedia learning (pp. 19-30). New York: Cambridge Espinosa University Press.

Schnotz, W., \& Bannert, M. (2003). Construction and interference in learning from multiple representation. Learning and Instruction, 13(2), 141-156.

Smith, M. U. (2010a). Current status of research in teaching and learning evolution: I. Philosophical/ epistemological issues. Science \& Education, 19(6-8), 523-538.

Smith, M. U. (2010b). Current status of research in teaching and learning evolution: II. Pedagogical issues. Science \& Education, 19(6-8), 539-571.

Smith, J. J., Baum, D. A., \& Moore, A. (2009). The need for molecular genetic perspectives in evolutionary education (and vice versa). Trends in Genetics, 25(10), 427-429.

Smith, C. H., \& Beccaloni, G. Editors (2008). Natural Selection and Beyond. The intellectual legacy of Alfred Russel Wallace. New York: Oxford University Press. 
Swarat, S., Light, G., Park, E. J., \& Drane, D. (2011). A typology of undergraduate students' conceptions of size and scale: identifying and characterizing conceptual variation. Journal of Research in Science Teaching, $48(5), 512-533$

Tasker, R., \& Dalton, R. (2008). Visualizing the molecular world - design, evaluation, and use of animations. In K. Gilbert, M. Reiner, \& M. Nakleh (Eds.), Visualization: Theory and practice in science education (pp. 103-131). Dordrecht: Springer.

Tenenbaum, J. B., Kemp, C., Griffiths, T. L., \& Goodman, N. D. (2011). How to grow a mind: statistics, structure, and abstraction. Science, 331(6022), 1279-1285.

Tsui, C.-Y. (2003). Genetics reasoning with multiple external representations. Research in Science Education, 33(1), 111-135.

Tsui, C.-Y., \& Treagust, D. F. (2012). Introduction to multiple representations: their importance in biology and biological education. In Multiple Representations in Biological Education Treagust, D. F., \& Tsui, C.-Y. (Eds.) (Vol. 7, pp. 3-18). Dordrecht: Springer Netherlands.

Tversky, B., Morrison, J. B., \& Betrancourt, M. (2002). Animation: can it facilitate? International Journal of Human Computer Studies, 57, 247-262.

van Mil, M. H. W., Postma, P. A., Boerwinkel, D. J., Klaasen, K., \& Waarlo, A. J. (2016). Molecular mechanistic reasoning: toward bridging the gap between the molecular and cellular levels in life science education. Science Education, 100, 517-585.

White, P. J. T., Heidemann, M. K., \& Smith, J. J. (2013). A new integrative approach to evolution education. Bioscience, 63(7), 586-594.

Witteman, H. O., Fuhrel-Forbis, A., Wijeysundera, H. C., Exe, N., Dickson, M., Holtzman, L., et al. (2014). Animated randomness, avatars, movement, and personalization in risk graphics. Journal of Medical Internet Research, 16(3), e80. https://doi.org/10.2196/jmir.2895

Wu, H.-K., Krajcik, J. S., \& Soloway, E. (2001). Promoting understanding of chemical representations: students' use of a visualization tool in the classroom. Journal of Research in Science Teaching, 38(7), 821-842.

Yasri, P., \& Mancy, R. (2012). Understanding student approaches to learning evolution in the context of their perceptions of the relationship between science and religion. International Journal of Science Education., $36(1), 24-45$. 